\title{
Non-antibiotic compounds affecting the growth of urinary pathogens during urine culture: a preliminary in vitro study
}

\author{
MÁRIÓ GAJDÁCS ${ }^{1,2^{*}}$ \\ ${ }^{1}$ Department of Pharmcodynamics and Biopharmacy, University of Szeged, Szeged, Hungary \\ ${ }^{2}$ Department of Medical Microbiology, Semmelweis University, Budapest, Hungary \\ *Corresponding author: Márió Gajdács \\ Email: mariopharma92@gmail.com
}

Received: 14 July 2020 / Revised: 10 August 2020 / Accepted: 11 August 2020

\begin{abstract}
Introduction: Urine samples are one of the most frequently submitted samples for culture to clinical microbiology laboratories, exceeding the number of most of the other clinical sample types. Various non-antibiotic pharmaceutical compounds may have inhibitory properties on bacteria, as many of these agents accumlate in/eliminated through urine.

Aims: The aim of our present study is to screen various non-antibiotic group pharmacological agents in vitro for their potential to augment the viability of pathogenic bacteria in urine samples.

Methods: Sixty (n=60) pharmacological agents were tested during our experiments. Bacillus subtilis ATCC 6633, Escherichia coli ATCC 25922, Klebsiella pneumoniae ATCC 700603 (ESBL-producing) and Staphylococcus aureus ATCC 29213 were the bacterial strains utilized in this study. Detection of inhibitory activity among the tested compounds was performed on Mueller-Hinton plates, using disk diffusion method.

Results: Nineteen $(n=19)$ compounds presented with various levels of inhibitory activity on the tested bacterial strains (four compounds for K. pneumoniae, seven compounds on E. coli and sixteen compounds on S. aureus). The compounds showed the highest levels of inhibitory activity on B. subtilis ATCC 6633, which is one of the main bacterial strains used for the screening of the 'intrinsic' antibacterial activity of urine.

Conclusion: During urinalysis, all possible confounding variables must be taken into consideration, which may distort the culture results of routine laboratories. Our results suggest that further experiments, involving additional pharmacological agents is warranted, to establish the full extent of their influence on the appropriate culture of urine samples.
\end{abstract}

Keywords: urinary tract infections; urinalysis; intrinsic antibacterial activity; non-antibiotics; antimicrobials; drug repurosing; disk diffusion; Bacillus subtilis

\section{Introduction}

Urinary tract infections (UTIs) are one of the most common infectious pathologies worldwide (following lower respiratory tract infections and gastrointestinal infections) [1,2]. From the standpoint of public health, UTIs represent an important factor or morbidity and mortality, affecting both patients in primary care and tertiary care settings [3]. In fact, according to some estimates, around 50$60 \%$ of women in the age range of $20-40$ years experience a UTI at least once during their lifetime, while nosocomial UTIs may represent $25-50 \%$ of hospital-acquired infections overall [4]. The diagnosis and management of UTIs, and the corresponding lost working days associated with these infections also have a significant economic consequence, estimated to be around 3-5 billion US dollars annually $[5,6]$. Uncomplicated UTIs are principally associated with members of the intestinal flora, with Escherichia coli representing $50-90 \%$ of these etiologies [7,8]; the spectrum of pathogens assicoated with nosocomial infections is more diverse, including non-fermenting Gram-negative bacteria, Gram-positive cocci (Staphylococcus aureus, S. saphrophyticus, Enterococcus spp.) and Candida spp [9-11]. UTIs are associated with a variety of clinical signs and symptoms, including the burning sensation in the genitourinary region, strong and persistent urge to urinate, small volume of voided urine, urinary incontinence, pelvic pain, fever and nausea/vomiting [12]. Additionally, the color and consistency of the voided urine may be also subject to changes (cludy, red, bright pink, bloody, and foul-smelling urine) [12,13].

Urine samples (more commonly clean-catch/ midstream and catheter-specimen urine) are one of the most frequently submitted samples for culture to the clinical microbiology laboratories, exceeding the number of most of the other clinical 
sample types [14]. Clean-catch urine samples are an inexpensive and non-invasive without the risk of complications; although contamination of the sample with the normal flora or the distal urethrea is a risk, the appropriate instruction of patients regarding hygienic considerations and sample collection is usually adequate for appropriate samples to be attained [15]. Nevertheless, collection of urine by using a single catherer is a more appropriate method to use to avoid contamination in hospitalized patients $[1,2,15]$. Bacteriological culture of urine samples on non-selective or chromogenic media (frequently coupled with the use of nitrite and leukocyte-esterase tests or a hemocytometer) is the gold standard method in the etiological diagnosis of UTIs. The interpretation of culture results (usually $\geq 10^{5}$ colony forming units/ $\mathrm{mL}$ corresponding to singificant bacteriuria) from urine samples provide little or no challenge to clinical microbiologists [16]. Based on data from the literature, $50-70 \%$ of urine cultues are culturenegative, while out of the positive urine samples, $40-50 \%$ of isolated bacteria are relevant urinary pathogens [17]. Sample procurement, time elapsed before sample processing and expertise of the staff are all relevant factors in establishing the etiology of UTIs. However, some additional factors may influcence the results of succesful interpretation of urine cultues. It it well-known that microbiological sampling should preferably be carried out before the administration of antibiotics, as these drugs may lead to false negative results (inhibiting or significantly reducing bacterial growth), misleading clinicians and microbiologists [18]. To screen for this, routine microbiology laboratories often perform ancillary tests with pan-susceptible bacterial strains (e.g., Bacillus spp., E. coli) to assess the intrinsic antibacterial activity of the urine samples [19]. If these tests prove to be positive, clinical microbiologists may observe different rules during interpretation of culture results.

Nevertheless, there is increasing evidence that various non-antibiotic pharmaceutical compounds may also have inhibitory properties on bacteria [20]; as a part of drug repurposing advances, several drugs have also been screened for their antimicrobial properties [21]. In addition, the pharmacokinetic properties of these drugs should also be taken into consideration, as many of these agents accumlate in/eliminated through urine, thus, they may possess the potency to adversely affect the growth of uropathogenic bacteria [22]. Therefore, the aim of our present study is to screen various non-antibiotic group pharmacological agents in vitro for their potential to augment the viability of pathogenic bacteria in urine samples or their growth on culture media during urinalysis.

\section{Materials and Methods}

\subsection{Chemicals}

Sixty $(\mathrm{n}=60)$ pharmacological agents, encompassing a wide variety of different chemical structures and mechanisms of action were tested during our experiments: acetylsalicylic acid (SigmaAldrich; Budapest, Hungary; will be listed as SA in the subsequent text), acetaminophen (SA), acetyl-cysteine (Teva Pharmaceuticals; Petah Tikva, Israel; will be listed as $\mathrm{TPh}$ in the subsequent text), acyclovir (TPh), allopurinole (SA), amantadine (SA), ambroxol (TPh), atorvastatin (SA), atracurium (SA), azelastine (SA), bleomycin (TPh), cisplatin (TPh), celecoxib (Pfizer Hungary Ltd.; Budapest, Hungary), cetirizine (SA), chlorpromazine (SA), chloroxazone (SA), cidofovir (SA), clotrimazole $(\mathrm{TPh})$, cyclophosphamide (Baxter; Deerfield, IL, United States), diclofenac (SA), doxorubicin $(\mathrm{TPh})$, enalapril maleate $(\mathrm{SA})$, etodolac (SA), famotidine (SA), fluconazole (SA), fluoxetine (SA), gemcitabine (TPh), guaifenesin (SA), indomethacin (Sanofi; Paris, France; will be listed as $\mathrm{SP}$ in the subsequent text), imipramine (SA), ivermectin (SA), metamizole-sodium (SF), mebendazole (Richter Pharmaceuticals; Budapest, Hungary; will be listed as $\mathrm{RPh}$ in the subsequent text), lidocaine (SA), metoprolol succinate (SA), paclitaxel (TPh), prazozin (SA), metformin (SA), methotrexate (Ebewe Pharma, Unterach am Attersee, Austria), prilocaine (SA), promethazine (SA), risperidone (SA), simvastatin (SA), sitagliptine (SA), suxamethonium (SA), terbinafine (GlaxoSmithKline Hungary Ltd., Budapest, Hungary), thioridazine (SA), topotecan (SA), valsartan (SA), verapamil $(\mathrm{TPh})$, vincristine $(\mathrm{TPh})$, xylomethazoline

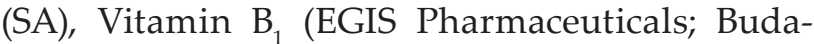
pest, Hungary; will be listed as EGIS in the subsequent text), Vitamin $B_{6}$ (EGIS), Vitamin $B_{12}$ $(\mathrm{RPh})$, Vitamin C (SA), Vitamin D (EGIS), Vitamin E (SA), Vitamin K (SA) and 5-fluorouracil (TPh). The compounds were chosen on a basis of being substrates of the organic cation transporter-2 (OCT2/SLC22A2), organic anion transporters 1 and/or 3 (OAT1/SCL22A6 and OAT3/SCL22A8) and multi-antimicrobial extrusion protein (MATE), which are all relevant transporters in 
the renal elimination of various pharmacological agents [23]. The list of relevant substrates was acquired from the DrugBank database (https:// www.drugbank.ca/).

Pharmaceutical compounds were dissolved in phosphate-buffered saline, with the exception of simvastatin and atorvastatin, which were dissolved in dimethyl sulfoxide (DMSO), in addition to Vitamin D and Vitamin K, which were dissolved in acetone and 70\% ethanol, respectively. The final concentration of the tested compounds was set at $100 \mu \mathrm{g} / \mathrm{mL}$ in the experiments.

\subsection{Bacterial strains}

The following bacterial strains were used during our growth inhibition experiments: Bacillus subtilis ATCC 6633, Escherichia coli ATCC 25922, Klebsiella pneumoniae ATCC 700603 (ESBL-producing) and Staphylococcus aureus ATCC 29213.

\subsection{Culture media, paper disks}

Bacterial strains were maintained on blood agar and eosine methylene blue plates (bioMérieux, Marcy-l'Étoile, France). Inhibitory activity of the tested compounds was investigated on MuellerHinton agar plates (bioMérieux, Marcy-l'Étoile, France).

Filter paper disks $(7.0 \mathrm{~mm}$ in diameter, Whatman 3MM) were impregnated with the solutions of the tested compounds. Ciprofloxacin $(5 \mu \mathrm{g})$, meropenem $(10 \mu \mathrm{g})$ and trimethoprim/sulfamethoxazole $(1.25 / 23.75 \mu \mathrm{g})$ disks (Liofilchem, Abruzzo, Italy) were used in the control experiments.

\subsection{Inhibitory activity of non-antibiotic drugs}

Detection of inhibitory activity among the tested compounds was performed on MHA plates, containing B. subtilis ATCC 6633 spores [22,24,25]. A maximum of 6 sterile filter paper discs (impregnated with $10 \mu \mathrm{L}$ of the solutions of the solutions of different the tested compounds) were placed on MHA, containing a B. subtilis spore suspension (250 $\mu \mathrm{l}$ per 1 liters). Control strains (S. aureus, E. coli and K. pneumoniae) were plated on MHA agar conventionally, and the sterile filter paper discs were placed on the inoculated plates. The plates were incubated at $37{ }^{\circ} \mathrm{C}$ in an air thermostat. The inhibitory activity of the tested compounds was assessed semi-quantitatively; the zone of inhibition around the disks impregnated with the solu- tions of the tested compounds were recorded after 16-18 $\mathrm{h}$ of incubation, using a caliper (expressed as milimeters \pm standard deviation [SD]). Any measureable zone of inhibition was considered as positive $[22,24,25]$. DMSO (at $2 \mathrm{~V} / \mathrm{V} \%$ concentration) was used as a negative control for the tested compounds, while ciprofloxacin, meropenem and trimethoprim/sulfamethoxazole disks were used as positive controls. All experiments were performed in triplicate.

\section{Results}

Out of the 60 tested pharmacological agents, nineteen $(n=19)$ compounds presented with various levels of inhibitory activity on the tested bacterial strains. The results of our disk diffusion inhibitory experiments are presented in Table I. Out of the nineteen compounds, four compounds (atracurium, doxorubicin, lidocaine, thioridazine) showed measurable inhibition zones on $K$. pneumoniae ATCC 700603 (ranging between 2-6 mm), while seven compounds (atracurium, celecoxib, chlorpromazine, doxorubicin, imipramine, lidocaine, thioridazine) showed inhibitory activity on E. coli ATCC 25922 (with zone diameters ranging between 1-7 mm). S. aureus ATCC 29213 was more susceptible to the inhibitory activity of the tested drugs (zone diameters ranging between 4-14 mm; for 16 out of the 19 compounds), with the exception of allopurinole, methotrexate and verapamil). The compounds showed the highest levels of inhibitory activity on B. subtilis ATCC 6633, which is one of the main bacterial strains used for the screening of the 'intrinsic' antibacterial activity of urine; with zone diameters ranging between $4 \mathrm{~mm}$ (allopurinole) and $22 \mathrm{~mm}$ (thioridazine). All tested reference antibiotics showed zone diameters for the respective bacterial strains, which corresponded to the 'susceptible' therapeutic category (based on EUCAST v. 9.0 breakpoints). 2 V/V\% DMSO did not show any inhibitory activity during the experiments.

\section{Discussion}

UTIs are a major publich health and economic burden to healthcare infrastructres worldwide, therefore the correct determination of the etiological agents in these infections in of utmost importance $[1-3,5,11,25,26]$. During urinalysis, all possible confounding variables must be taken into consideration, which may distort the culture re- 
Table I Inhibitory activity of tested pharmaceutical compounds (results expressed as $m m \pm S D$ )

\begin{tabular}{|c|c|c|c|c|}
\hline & $\begin{array}{l}\text { Bacillus subtilis } \\
\quad \text { ATCC } 6633\end{array}$ & $\begin{array}{l}\text { Escherichia coli } \\
\text { ATCC } 25922\end{array}$ & $\begin{array}{c}\text { Klebsiella } \\
\text { pneumoniae } \\
\text { ATCC } 700603\end{array}$ & $\begin{array}{c}\text { Staphylococcus } \\
\text { aureus } \\
\text { ATCC } 29213\end{array}$ \\
\hline Allopurinole & $4 \pm 1$ & $\varnothing$ & $\varnothing$ & $\varnothing$ \\
\hline Atorvastatin & $11 \pm 2$ & $\varnothing$ & $\varnothing$ & $8 \pm 2$ \\
\hline Atracurium & $14 \pm 2$ & $5 \pm 1$ & $3 \pm 1$ & $6 \pm 1$ \\
\hline Bleomycin & $16 \pm 2$ & $\varnothing$ & $\varnothing$ & $8 \pm 3$ \\
\hline Celecoxib & $20 \pm 3$ & $1 \pm 1$ & $\varnothing$ & $14 \pm 2$ \\
\hline Chlorpromazine & $17 \pm 3$ & $3 \pm 1$ & $\varnothing$ & $10 \pm 2$ \\
\hline Clotrimazole & $15 \pm 2$ & $\varnothing$ & $\varnothing$ & $5 \pm 2$ \\
\hline Doxorubicin & $18 \pm 3$ & $5 \pm 2$ & $5 \pm 1$ & $8 \pm 2$ \\
\hline Etodolac & $15 \pm 3$ & $\varnothing$ & $\varnothing$ & $7 \pm 1$ \\
\hline Fluconazole & $17 \pm 1$ & $\varnothing$ & $\varnothing$ & $7 \pm 2$ \\
\hline Imipramine & $9 \pm 2$ & $3 \pm 3$ & $\varnothing$ & $4 \pm 2$ \\
\hline Ivermectin & $14 \pm 3$ & $\varnothing$ & $\varnothing$ & $8 \pm 3$ \\
\hline Lidocaine & $17 \pm 4$ & $7 \pm 2$ & $6 \pm 1$ & $10 \pm 3$ \\
\hline Mebendazole & $16 \pm 1$ & $\varnothing$ & $\varnothing$ & $12 \pm 2$ \\
\hline Methotrexate & $10 \pm 2$ & $\varnothing$ & $\varnothing$ & $\varnothing$ \\
\hline Promethazine & $7 \pm 2$ & $\varnothing$ & $\varnothing$ & $6 \pm 3$ \\
\hline Simvastatin & $13 \pm 2$ & $\varnothing$ & $\varnothing$ & $10 \pm 2$ \\
\hline Thioridazine & $22 \pm 4$ & $5 \pm 1$ & $2 \pm 1$ & $9 \pm 3$ \\
\hline Verapamil & $6 \pm 3$ & $\varnothing$ & $\varnothing$ & $\varnothing$ \\
\hline Ciprofloxacin $(5 \mu \mathrm{g})$ & $24 \pm 3$ & $27 \pm 3$ & $26 \pm 2$ & $26 \pm 2$ \\
\hline Meropenem $(10 \mu \mathrm{g})$ & $29 \pm 2$ & $24 \pm 1$ & $23 \pm 1$ & $24 \pm 1$ \\
\hline $\begin{array}{l}\text { Trimethoprim/sulfamethoxazole } \\
(1.25 / 23.75 \mu \mathrm{g})\end{array}$ & $16 \pm 3$ & $19 \pm 1$ & $18 \pm 2$ & $16 \pm 2$ \\
\hline
\end{tabular}

Ø: no inhibition zones were observed

sults of routine laboratories. These may include issues during sample procurement and time elapsed before sample has been processed (i.e. the pre-analytical phase), however, troubleshooting must also encompass steps in the analytical phase [27]. The chemical composition of urine clearly affects the viability and species-composition of bacteria, for example, if the $\mathrm{pH}$ of the urine shifts in either directions, it may inhibit or potentiate the replication of several microorganisms [26,27]. Many natural compounds and constituents of our diet have well-known antibacterial properies (e.g., ajoene [28], betulinic acid [29], cranberry juice [30], curcumin [31], essential oils [32], horse raddish [33], pepper [34], resveratrol [35] and zeaxantin [36]), which may influence bacterial viability in urine. Nevertheless, the relevance of non-antibiotic compounds in this regard must not be underestimated [20,21,37]; this is especially true in case of older patients, whom many drugs are simulate- nously prescribed [38]. In our study, nineteen out of the sixty tested pharmacological agents presented with growth inhibitory properties on the tested bacterial strains. With the inclusion of $S$. aureus, E. coli and K. pneumoniae in the study, we aimed to assess the relevance of these drugs in decreasing the viability of pathogenic bacteria in urine; in contrast, the B. subtilis strain is predominantly used to provide information on the antibacterial activity of the urine sample itself. While 4-16 compounds (depending on the bacterial strain) showed growth inhibitory activity on the reference strain, $\mathrm{n}=19$ drugs inhibited the growth of $B$. subtilis in the disk diffusion tests to various extents. This experiental result may point out that in addition to antibiotics, non-pharmacological agents may also be responsible to "positive” tests, when assessing the antibacterial activity of the urine samples received, depending on the concentration, in which they are available in the 
urine [22]. Similarly to our results, the potential antibacterial activity of azole antifungal agents [39], antracyclines [40], phenothiazines [41], local and general anesthetics [42], peripherially acting muscle relaxants [43], non-steroidal anti-inflammatory drugs [44] and statins [45] were already demonstrated by studies in different settings. However, other studies also highlighted the antibacterial properties of acetyl-salicylic acid [46], allopurinole [47], various cardio-vascular medications [48], and several vitamins (A, C, D and K) [49-52]; this was not demonstrated in our in vitro settings.

\section{Conclusions}

In conclusion, the aim of our present study was produce in vitro data on the possible role of nonantibiotic pharmacological agents, as inhibitors of growth during urinalysis, i.e. the culture of urine samples on bacteriological media, if a UTI is suspected. Our results show that a wide variety of structurally unrelated drugs may have the potential to inhibit the growth of urinary pathogens, or B. subtilis, a commonly used microorganism in ancillary tests. Although the methodology used during our experients (disk diffusion) offers only preliminary, semi-quantitative results and the experiments were carried out in a select group of bacteria, our results suggest that further experiments, involving additional pharmacological agents is warranted, to establish the full extent of their influence on the appropriate culture of urine samples.

\section{Funding}

M.G. was supported by the János Bolyai Research Scholarship (BO/00144/20/5) of the Hungarian Academy of Sciences. The research was supported by the UNKP-20-5-SZTE-330 New National Excellence Program of the Ministry for Innovation and Technology from the source of the National Research, Development and Innovation Fund. Support from Ministry of Human Capacities, Hungary grant 20391-3/2018/FEKUSTRAT is acknowledged. M.G. would also like to acknowledge the support of ESCMID's “30 under 30" Award.

\section{Conflicts of interest}

The author declares no conflict of interest, monetary or otherwise.

\section{References}

1. Gupta K, Hooton TM, Naber KG, Wullt B, Colgan R, Miller LG, et al. International clinical practice guidelines for the treatment of acute uncomplicated cystitis and pyelonephritis in women: A 2010 update by the Infectious Diseases Society of America and the European Society for Microbiology and Infectious Diseases. Clin Infect Dis 2011;52:e103-e120. https:// doi.org/10.1093/cid/ciq257

2. Hooton TM, Bradley SF, Cardenas DD, Colgan R, Geerlings SE, Rice JC, et al. Diagnosis, Prevention, and Treatment of Catheter-Associated Urinary Tract Infection in Adults: 2009 International Clinical Practice Guidelines from the Infectious Diseases Society of America. Clin Infect Dis 2010;50:625-663. https:// doi.org/10.1086/650482

3. Tandogdu Z, Wagenlehner FM. Global epidemiology of urinary tract infections. Curr Opin Infect Dis 2016;29:73-79. https://doi.org/10.1097/ QCO.0000000000000228

4. Negus M, Phillips C, Hindley R. Recurrent urinary tract infections: a critical review of the currently available treatment options. Obstet Gynecol 2019; https://doi.org/10.1111/tog.12644 https://doi. org/10.1111/tog.12644

5. Hozzari A, Benhzadi P, Khiabani PK, Sholeh M, Sabokroo. Clinical cases, drug resistance, and virulence genes profiling in Uropathogenic Escherichia coli. J Appl Gen 2020;61:265-273. https://doi. org/10.1007/s13353-020-00542-y

6. Ciani O, Grassi D, Tarricone R. An economic perspective on urinary tract infection: the "costs of resignation". Clin Drug Investig 2013;33:255-261. https://doi.org/10.1007/s40261-013-0069-x

7. Gajdács M, Ábrók M, Lázár A, Burián K. Comparative Epidemiology and Resistance Trends of Common Urinary Pathogens in a Tertiary-Care Hospital: A 10-Year Surveillance Study. Medicina 2019;55:e356. https://doi.org/10.3390/medicina55070356

8. Yang B, Yang F, Wang S, Wang Q, Liu Z, Feng W, et al. Analysis of the spectrum and antibiotic resistance of uropathogens in outpatients a tertiary hospital. J Chemother 2018;30:145-149. https://doi.org/10.1080/ 1120009X.2017.1418646

9. Gajdács M, Dóczi I, Ábrók M, Lázár A, Burián K. Epidemiology of candiduria and Candida urinary tract infections in inpatients and outpatients: Results from a 10-year retrospective survey. Cent Eur J Urol 2019;72:209-214.

10. Gajdács M, Burián K, Terhes G. Resistance Levels and Epidemiology of Non-Fermenting Gram-Negative Bacteria in Urinary Tract Infections of Inpatients and Outpatients (RENFUTI): A 10-Year Epidemiological Snapshot. Antibiotics 2019;8:e143. https://doi. org/10.3390/antibiotics8030143

11. Behzadi P, Behzadi E, Ranjbar R. Urinary tract infections and Candida albicans. Cent Eur J Urol 2015;68:96101. https://doi.org/10.5173/ceju.2015.01.474 
12. Di Vico T, Morganti R, Cai T, Naber KG, Wagenlehner FME, Pilatz A, Alidjanov J, Morelli G, Bartoletti R. Acute Cystitis Symptom Score (ACSS): Clinical Validation of the Italian Version. Antibiotics 2020;9:e104. https://doi.org/10.3390/antibiotics9030104

13. Foxman B, Brown P. Epidemiology of urinary tract infections: Transmission and risk factors, incidence, and costs. Infect Dis Clin North Am 2003;17:227-241. https://doi.org/10.1016/S0891-5520(03)00005-9

14. Melia M. Bacterial Cystitis, Acute, Uncomplicated [Internet]. John Hopkins Antibiotic Guide; 2017. Available from: https://www.hopkinsguides.com/hopkins/view/Johns_Hopkins_ABX_ Guide/540046/all/Bacterial_Cystitis_Acute_ Uncomplicated? $q=$ cystitis

15. Wilson ML, Gaido L. Laboratory Diagnosis of Urinary Tract Infections in Adult Patients. Clin Infect Dis 2004;38:1150-1158. https://doi.org/10.1086/383029

16. Nicolle EL. Catheter associated urinary tract infections. Antimicrob Resist Infect Control 2014;3:e23. https://doi.org/10.1186/2047-2994-3-23

17. Stefaniuk E, Suchocka U, Bosacka K, Hryniewicz W. Etiology and antibiotic susceptibility of bacterial pathogens responsible for community-acquired urinary tract infections in Poland. Eur J Clin Microbiol Infect Dis 2016;35:1-7. https://doi.org/10.1007/ s10096-016-2673-1

18. Li L, Xu L, Zhu R, Song J, Wang X. Effect of prior receipt of antibiotics on the pathogen distribution: a retrospective observational cohort study on 27,792 patients. BMC Infect Dis 2020;20:e8. https://doi. org/10.1186/s12879-019-4724-6

19. Gajdács M, Urbán E. Resistance Trends and Epidemiology of Citrobacter-Enterobacter-Serratia in Urinary Tract Infections of Inpatients and Outpatients (RECESUTI): A 10-Year Survey. Medicina 2019;55:e285. https://doi.org/10.3390/medicina55060285

20. Gajdács M, Spengler G. The Role of Drug Repurposing in the Development of Novel Antimicrobial Drugs: Non-Antibiotic Pharmacological Agents as Quorum Sensing-Inhibitors. Antibiotics 2019;8:e270. https://doi.org/10.3390/antibiotics8040270

21. Pushpakom S, Iorio F, Eyers PA, Escott KJ, Hopper S, Wells A, Doig A, Guilliams T, Latimer J, McNamee C, Norris A, Sanseau P, Cavalla D, Pirmohamed M. Drug repurposing: progress, challenges and recommendations. Nat Rev Drug Discov 2019;18:41-58. https://doi.org/10.1038/nrd.2018.168

22. Jufer RA, Wstadik A, Walsh SL, Levine BS, Cone EJ. Elimination of Cocaine and Metabolites in Plasma, Saliva, and Urine Following Repeated Oral Administration to Human Volunteers. J Anal Tox 2000;24:467477. https://doi.org/10.1093/jat/24.7.467

23. Roth M, Obaidat A, Hagenbuch B. OATPs, OATs and OCTs: the organic anion and cation transporters of the SLCO and SLC22A gene superfamilies. Br J Pharmacol 2012;165:1260-1287. https://doi.org/10.1111/ j.1476-5381.2011.01724.x

24. Kellogg JA, Manzella JP, Seiple JW, Fortina SJ, Cook
JW, Levisky JS. Efficacy of an Enzyme Linked Immunosorbent Assay for Detection of Urinary Tract Immunoglobulins for Diagnosis of Urinary Tract Infections. J Clin Microbiol 1992;30:1711-1715. https://doi. org/10.1128/JCM.30.7.1711-1715.1992

25. Murray PR, Smith TB, McKinney TC. Clinical evaluation of three urine screening tests. J Clin Microbiol 1987; 25: 467-470. https://doi.org/10.1128/ JCM.25.3.467-470.1987

26. Wiedemann B, Heisig A, Heisig P. Uncomplicated urinary tract infections and antibiotic resistanceepidemiological and mechanistic aspects. Antibiotics 2014;3:341-352. https://doi.org/10.3390/antibiotics3030341

27. Negus M, Phillips C, Hindley R. Recurrent urinary tract infections: a critical review of the currently available treatment options. Obstet Gynecol 2019; https://doi.org/10.1111/tog.12644 https://doi. org/10.1111/tog.12644

28. Jakobsen TH, van Gennip M, Phipps RK, Shanmugham MS, Christensen LD, Alhede M, Skindersoe ME, Rasmussen TB, Friedrich K, Uthe F, et al. Ajoene, a sulfur-rich molecule from garlic, inhibitsgenes controlled by quorum sensing. Antimicrob Agents Chemother 2012;56:2314-2325. https://doi. org/10.1128/AAC.05919-11

29. Rajkumari J, Borkotoky S, Murali A, Suchiang K, Mohanty SK, Busi S. Attenuation of quorum sensing controlled virulence factors and biofilm formation in Pseudomonas aeruginosa by pentacyclic triterpenes, betulin and betulinic acid. Microb Pathog.2018;118:48-60. https://doi.org/10.1016/j.micpath.2018.03.012

30. Sun J, Marais JPJ, Khoo C, LaPlante K, Vejborg RM, Givskov M, Tolker-Nielsen T, Seeram NP, Rowley DC. Cranberry (Vaccinium macrocarpon) oligosaccharides decrease biofilm formation by uropathogenic Escherichia coli. J Funct Foods 2015; 17: 235242. https://doi.org/10.1016/j.jff.2015.05.016

31. Ding T, Li T, Wang Z, Li J. Curcumin liposomes interfere with quorum sensing system of Aeromonas sobria and in silico analysis. Sci Rep 2017;7:1-16. https://doi.org/10.1038/s41598-017-08986-9

32. Poli JP, Guinoiseau E, de Rocca Serra D, Sutour S, Paoli M, Tomi F, Quilichini Y, Berti L, Lorenzi V. Anti-Quorum Sensing Activity of 12 Essential Oils on chromobacterium violaceum and Specific Action of cis-cis-p-Menthenolide from Corsican Mentha suaveolens ssp. Insularis. Molecules 2018; 23: 2125. https://doi.org/10.3390/molecules23092125

33. Jakobsen TH, Bragason SK, Phipps RK, Christensen LD, van Gennip M, Alhede M, Skindersoe M, Larsen TO, Høiby N, Bjarnsholt T, et al. Food as a source for quorum sensing inhibitors: Iberin from horseradish revealed as a quorum sensing inhibitor of Pseudomonas aeruginosa. Appl Environ Microbiol 2012; 78: 2410-2421 https://doi.org/10.1128/ AEM.05992-11

34. Givskov M. Beyond nutrition: Health-promoting 
foods by quorum-sensing inhibition. Future Microbiol 2012;7:1025-1028 https://doi.org/10.2217/ fmb.12.84

35. Duan J, Li M, Hao Z, Shen X, Liu L, Jin Y, Wang S, Guo Y, Yang L, Wang L, et al. Subinhibitory concentrations of resveratrol reduce alpha-hemolysin production in Staphylococcus aureus isolates by downregulating saeRS. Emerg Microbes Infect 2018; 7: 1-10. https://doi.org/10.1038/s41426-018-0142-x

36. Gökalsın B, Aksoydan B, Erman B, Sesal NC. Reducing Virulence and Biofilm of Pseudomonas aeruginosa by Potential Quorum Sensing Inhibitor Carotenoid: Zeaxanthin. Microb Ecol 2017;74:466-473. https://doi.org/10.1007/s00248-017-0949-3

37. Ashburn TT, Thor KB. Drug repositioning: identifying and developing new uses for existing drugs. Nat Rev Drug Discov 2004;3:673-684. https:/doi. org/10.1038/nrd1468

38. Maher RL, Hanlon JT, Hajjar ER. Clinical Consequences of Polypharmacy in Elderly. Exper Opin Drug Saf 2014;13: 10.1517/14740338.2013.827660 https://doi.org/10.1517/14740338.2013.827660

39. D’Angelo F, Baldelli V, Halliday N, Pantalone P, Polticelli F, Fiscarelli E, Williams P, Visca P, Leoni L, Rampioni G. Identification of FDA-Approved Drugs as Antivirulence Agents Targeting the pqs QuorumSensing System of Pseudomonas aeruginosa. Antimicrob Agents Chemother 2018;62:e01296-e01318. https://doi.org/10.1128/AAC.01296-18

40. Cox G, Koteva K, Wright GD. An unusual class of anthracyclines potentiate Gram-positive antibiotics in intrinsically resistant Gram-negative bacteria. J Antimicrob Chemother 2014;69:1844-1855. https:// doi.org/10.1093/jac/dku057

41. Amaral L, Viveiros M, Molnár J. Antimicrobial activity of phenothiazines. In vivo 2004;18:725-731.

42. Johnson SM, Saint John BE, Dine AP. Local Anesthetics as Antimicrobial Agents: A Review. Surg Infect 2008;9:205-213. https://doi.org/10.1089/sur.2007.036

43. Imani F, Mubarak SMH, Mostafavi SKS, KhodaBakhshi M, Bojari MR, Ghasemian A. Antibacterial effects of local analgesics and anesthetics. Rev Med Microbiol 2020; 31: 47-50. https://doi.org/10.1097/ MRM.0000000000000193

44. Hendrix AS, Spoonmore TJ, Wilde AD, Putnam NE, Hammer ND, Snyder DJ, Guelcher SA, Skaa EP, Cassat JE. Repurposing the Nonsteroidal Anti-inflammatory Drug Diflunisal as an Osteoprotective, Antivirulence Therapy for Staphylococcus aureus Osteomyelitis.
Antimicrob Agents Chemother 2016;60:5322-5330. https://doi.org/10.1128/AAC.00834-16

45. Ko HHT, Lareu RR, Dix BR, Hughes JD. Statins: Antimicrobial resistance breakers or makers? PeerJ 2017;5:e3952 https://doi.org/10.7717/peerj.3952

46. Al-Bakri AG, Othman G, Bustanji Y. The assessment of the antibacterial and antifungal activities of aspirin, EDTA and aspirin-EDTA combination and their effectiveness as antibiofilm agents. J Appl Microbiol 2009; 107: 280-286. https://doi.org/10.1111/j.13652672.2009.04205.x

47. Naftalin CM, Verma R, Gurumurthy M, Lu Q, Zimmerman M, Yeo BCM, Tan KH, Lin W, Yu B, Dertois V, Paton NI. Coadministration of Allopurinol To Increase Antimycobacterial Efficacy of Pyrazinamide as Evaluated in a Whole-Blood Bactericidal Activity Model 2017;61:1-10. https://doi.org/10.1128/ AAC.00482-17

48. Kumar R, Harilal S, Gupta SV, Jose J, Parambi DGT, Uddin S, Shah MA, Mathew B. Exploring the new horizons of drug repurposing: A vital tool for turning hard work into smart work. Eur J Med Chem 2019;182:111602. https://doi.org/10.1016/j.ejmech.2019.111602

49. Tintino SR, Morais-Tintino, CD, Campina FF, Pereira RL, Costa MS, Braga MFBM, Limaverde PW, Andrade JC, Siqueira-Junior JC, Coutinho HDM, et al. Action of cholecalciferol and alpha-tocopherol on Staphylococcus aureus efflux pumps. EXCLIJ 2016;15:315-322.

50. Kwiecińska-Piróg J, Skowron K, Bogiel T, Białucha A, Przekwas J, Gospodarek-Komkowska E. Vitamin C in the Presence of Sub-Inhibitory Concentration of Aminoglycosides and Fluoroquinolones Alters Proteus mirabilis Biofilm Inhibitory Rate. Antibiotics 2019; 8: 116. https://doi.org/10.3390/antibiotics8030116

51. Andrade JC, Braga MFBM, Guedes GMM, Tintino SR, Freitas MA, Quintans LJ, Menezes IRA, Coutinho HDM. Cholecalciferol, Ergosterol, and Cholesterol Enhance the Antibiotic Activity of Drugs. Int J Vitam Nutr Res 2018;88:244-250. https://doi. org/10.1024/0300-9831/a000268

52. Andrade JC, Braga MFBM, Guedes GMM, Tintino SR, Freitas MA, Menezes IRA, Coutinho HDM. Enhancement of the antibiotic activity of aminoglycosides by alpha-tocopherol and other cholesterol derivates. Biomed Pharmacother 2014;68:1065-1069. https://doi.org/10.1016/j.biopha.2014.10.011 